\title{
Power losses reduction of power transmission network using optimal location of low-level generation
}

\author{
Marwa M. Marei, Manal H. Nawer \\ Department of Electrical and Electronic Engineering, University of Kerbala, Iraq
}

\begin{tabular}{|c|c|}
\hline Article Info & ABSTRACT \\
\hline Article history: & Due to the growth of demand for electric power, electric power loss \\
\hline Received Jan 2, 2020 & $\begin{array}{l}\text { reduction takes great attention for the power utility. In this paper, a low-level } \\
\text { generation or distributed generation (DG) has been used for transmission }\end{array}$ \\
\hline Revised May 12, 2020 & power losses reduction. Karbala city transmission network (which is the case \\
\hline Accepted May 24, 2020 & $\begin{array}{l}\text { study) has been represented by using MATLAB m-file to study the load flow } \\
\text { and the power loss for it. The paper proposed the particle swarm optimization }\end{array}$ \\
\hline Keywords: & $\begin{array}{l}\text { (PSO) technique in order to find the optimal number and allocation of DG } \\
\text { with the objective to decrease power losses as possible. The results show }\end{array}$ \\
\hline Loss reduction & \\
\hline
\end{tabular}

Low-level generation

Particle swarm optimization

Power transmission network

Copyright $\odot 2020$ Institute of Advanced Engineering and Science. All rights reserved.

\section{Corresponding Author:}

Marwa M. Marei,

Department of Electrical and Electronic Engineering,

University of Kerbala, Iraq.

Email: marwa.alkhuzaei@uokerbala.edu.iq

\section{INTRODUCTION}

Losses reduction has great deals in power systems utility because the rising in cost of delivering electricity due to fuel cost rising to generate more power, and the global warming discomfort [1, 2]. Low-level generation is increasing in the last year because its great effect on improving electric network performance. It is defined as a low-level power generation source connected to the distribution network [3, 4]. It is used as another method to enhance the performance of electric power system [5, 6].

The positive effects of using this technique are as follows [7-11]:

- Decreasing power losses in transmission lines.

- Improving voltage level.

- Improving power quality.

- Short lead time.

- Its location near the load.

- Decreases cost.

- Maximum power demand reduction.

- Improving electric system reliability.

- Efficiency improving of the system.

- Possibility of renewable energy use.

- Reduced environmental impacts.

- Optimization techniques required for best number, size and placement of the low-level generation units [12-15].

In this work, the optimal number and location of low-level generation will be performed by using particle swarm optimization technique. PSO algorithm was incentive by the public behavior of creature such as fish and bird learning. PSO delivers a population-based explore process, in this process the individuals 
called particles (birds) to transposition their location (state) with time [16, 17]. In a PSO, particles (birds) fly round a multidimensional space. During the flying, each bird regularizes its location according to its private experiment, and the experiment of adjacent birds, making use of the optimal location accomplished by itself and its adjacent birds [18]. The direction of the swarm of a particle is recognized by the set of birds adjacent to the bird that want to optimize its location and its historical experiment $[19,20]$.

\section{KARBALA CITY TRANSMISSION NETWORK DESCRIPTION}

Karbala city transmission network shown in Figure 1 is correlating to the Iraqi power grid at three stations (Babylon (400/132/11) KV, Mussayab (400/132/11) KV, Khairat (400/132/11) KV. The Karbala transmission network consists from eleven substations; they are shown as follows:

- Five generation buses 1, 2, 3, 4, 5 that shown in Figure 1.

- $\quad$ Six load buses 6, 7, 8, 9, 10, 11 that shown in Figure 1.

- These substations connected by twelve transmission lines as shown in Figure 1.

Bus data and line data are illustrated in Tables (A.1) and (A.2) are shown in appendix.

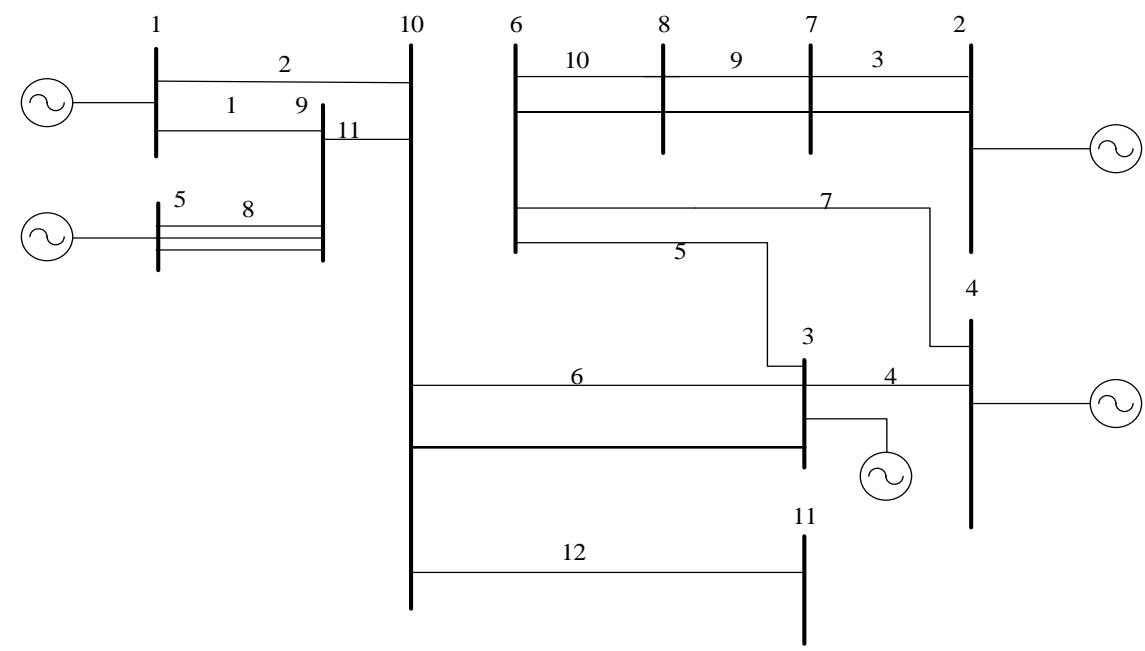

Figure 1. Karbala city transmission network

\section{PROBLEM FORMULATION}

\subsection{Load flow analysis}

At this work, both Newton-Raphson power flow method and PSO algorithm were used in the restriction of the optimum number and location of low-level generation units [21]. The Newton-Raphson power flow equation, at any given bus $i$ and $j$ are given as:

$$
\begin{aligned}
& P_{i}=\sum_{j=1}^{n}\left|V_{i}\right|\left|V_{j}\right|\left|Y_{i j}\right| \cos \left(\theta_{i j}-\delta_{i}+\delta_{j}\right) \\
& Q_{i}=-\sum_{j=1}^{n}\left|V_{i}\right|\left|V_{j}\right|\left|Y_{i j}\right| \sin \left(\theta_{i j}-\delta_{i}+\delta_{j}\right) \\
& \Delta P_{i}=P_{i}^{s p}-P_{i} \\
& \Delta Q_{i}=Q_{i}^{s p}-Q_{i}
\end{aligned}
$$

where,

$P_{i}^{s p}, Q_{i}^{s p}$ are the specified active and reactive power at the bus $i$ respectively.

$\mathrm{N}-\mathrm{R}$ load flow is expressed as: 


$$
\left[\begin{array}{l}
\Delta P \\
\Delta Q
\end{array}\right]=\left[\begin{array}{ll}
\frac{\partial P}{\partial \delta} & \frac{\partial P}{\partial V} \\
\frac{\partial Q}{\partial \delta} & \frac{\partial Q}{\partial V}
\end{array}\right]\left[\begin{array}{c}
\Delta \delta \\
\Delta|V|
\end{array}\right]
$$

The power loss required for the optimal location and size of the low-level generation units determination given in equation below:

$$
\begin{aligned}
P_{\text {Loss }}=\sum_{i=1}^{n} \sum_{j=1}^{n}\left(\frac{R_{i j} \cos \left(\delta_{i}-\delta_{j}\right)}{V_{i} V_{j}}\right)\left(P_{i} P_{j}+Q_{i} Q_{j}\right) \\
+\left(\frac{R_{i j} \sin \left(\delta_{i}-\delta_{j}\right)}{V_{i} V_{j}}\right)\left(Q_{i} P_{j}\right. \\
\left.-P_{i} Q_{j}\right)
\end{aligned}
$$

where,

$P_{i}, P_{j}, Q_{i}, Q_{j}$ : Active and reactive power of buses $i$ and $j$ respectively.

$R_{i j} \quad:$ Resistance of line between bus $i$ and $j$.

$V_{i}, V_{j}$ : The magnitude of bus voltage $i$ and $j$ respectively.

$\delta_{i}, \delta_{j}:$ Voltage angle of bus $i$ and bus $j$ respectively.

\subsection{PSO formulation}

As discuss earlier; in a PSO, birds get about round a multi- dimensional space expecting to optimal solution. During the flying, each bird regularizes its location according to its own experiment, and the experiments of adjacent birds, best location accomplished by itself and its adjacent birds has been used. According to that two significant best values results, one of these values is called pbest (personal best) and another best value is the gbest (global best) [22]. These values are the optimal values that has realized by any birds in the swarm. Each bird tries to change its location to a better location depending on the information listed below:

- The current positions and velocities.

- The distance between current position and pbest

- The distance between current position and gbest

The position (xi) and velocity (vi) of particle $i$ can be updated using (7) and (8) respectively:

$$
\begin{aligned}
\begin{aligned}
v_{i}^{k+1}=\omega v_{i}^{k}+c_{1} \text { rand } \times\left(\text { pbest }_{i}-s_{i}^{k}\right) \\
\\
+c_{2} \text { rand } \times\left(\text { gbest }_{i}-s_{i}^{k}\right)
\end{aligned} \\
x_{i}^{k+1}=x_{i}^{k}+v_{i}^{k+1}
\end{aligned}
$$

where,

$c_{1}, c_{2}$ : Positive constants.

rand : Random number in the range of 0 and 1.

$\omega \quad$ : Weight inertia.

The target of the optimal location algorithm is to decrease the total power loss of the power system, $P_{\text {Loss }}$ in (6). Flowchart of PSO shown in Figure 2.

\subsection{Active power loss index $\boldsymbol{P}_{L_{-} \text {index }}$}

The active power loss index is defined as:

$$
P_{L_{-} \text {index }}=\left(\frac{P_{L_{-} w D G}}{P_{L_{-} w o D G}}\right) \times 100 \%
$$

where;

$P_{L_{-} w D G}$ is the active power loss with DG.

$P_{L_{-} w o D G}$ is the active power loss without DG.

The lower value of this index indicates better operation of the power system in terms of active power loss reduction happened according to DG positioning and sizing [23-25]. 


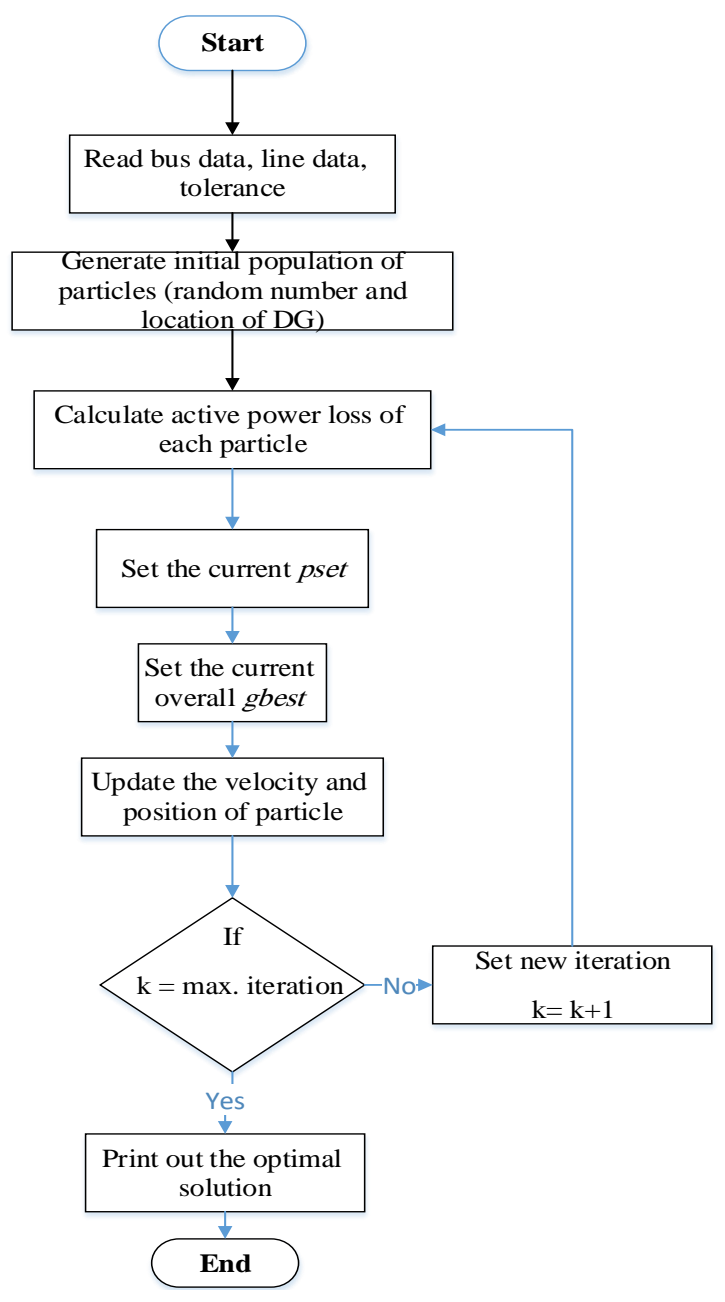

Figure 2. Flowchart for PSO of low-level generation optimal installation

\section{RESULTS AND ANALYSIS}

Karbala city transmission network has been analyzed by using MATLAB m-file to show the effect of using low-level generation in the transmission network. In the program the constrains for optimal size and location of low -level generation to be added to the network is selected as:

- The size of low-level generation not exceed $30 \mathrm{MW}$.

- It located at the load busses 6, 7, 8, 9, 10, 11 of the transmission networks.

PSO technique used to show optimal location for low-level generation installation as illustrated in the Table 1. From Table 1, the results show that the total losses for the system without low-level generation unitsis bigger than the total losses with low-level generation units; it is 39.507 MW without DG while it becomes less when a low-level generation unit used. Also, using PSO helps to select an optimal number and location of low-level generation units used to decrease the power losses as possible. It's obvious from the results that the optimal number is one low-level generation unit with a size of $30 \mathrm{MW}$ and located at the bus no. 7 which is a heavy loaded bus as shown in Appendix A Table (A.1). Table 2 lists the real power loss index for the system at different cases of DG insertion.

Table 1. Total power losses with and without using of low-level generation units

\begin{tabular}{cccc}
\hline No. of DG & Size of DG (MW) & Location & Total loss (MW) \\
\hline Without DG & & & 39.507 \\
3 & $10,10,10$ & $6,7,10$ & 30.067 \\
2 & 15,15 & 6,7 & 29.564 \\
1 & 30 & 7 & 26.549 \\
\hline
\end{tabular}


Also, using of low-level generation units in optimal location helps to decrease the losses in active power and that is affect the real power loss index. The results show that a lower real power index is achieved in case 3 (witch is indicate an optimal location and size for the low-level generation unit), where the index becomes 0.671 while it is 0.7609 in case 1 , this indicates that optimal location of low-level generation units insertion helps to decrease the active power loss.

Table 2. Real power loss index

\begin{tabular}{ccccc}
\hline Case & No. of DG & Size of DG (MW) & Location & $\boldsymbol{P}_{\text {Lindex }}$ \\
\hline 1 & 3 & $10,10,10$ & $6,7,10$ & 0.7609 \\
2 & 2 & 15,15 & 6,7 & 0.7107 \\
3 & 1 & 30 & 7 & 0.671 \\
\hline
\end{tabular}

\section{CONCLUSION}

PSO technique used to show optimal number location and size of low-level generation for a transmission network to reduce the total loss of the power system. The proposed optimization algorithm was applied to Karbala city (132/33) Kv. From the analysis and results shows above, it's clear that using of low-level generation helps to improve the performance of the transmission network and decreases the total losses for the system. Also, the selection of optimal location for low-level generation units is near the heavy loaded bus and this installation helps to decrease the total losses and improving the performance.

\section{APPENDIX}

Bus data and line data are illustrated in Tables (A.1) and (A.2).

Table (A.1). Karbala 132KV bus data

\begin{tabular}{ccccccccc}
\hline Bus no. & Bus Name & Type & $\mathrm{V}(\mathrm{pu})$ & $\delta$ & $\mathrm{Pg}(\mathrm{Mw})$ & $\mathrm{Qg}(\mathrm{Mw})$ & PL $(\mathrm{Mw})$ & QL $(\mathrm{Mw})$ \\
\hline 1 & Mussayab & 1 & 1.0 & 0 & 0 & 0 & 0 & 0 \\
2 & Babylon & 2 & 1.0 & 0 & 135 & 65.383 & 0 & 0 \\
3 & alghazia & 2 & 1.0 & 0 & 96.3 & 46.545 & 0 & 0 \\
4 & Khairat & 2 & 1.0 & 0 & 135 & 65.383 & 0 & 0 \\
5 & STX & 2 & 1.0 & 0 & 99 & 47.85 & 0 & 0 \\
6 & West of Karbala & 3 & 1.0 & 0 & 0 & 0 & 154 & 74.585 \\
7 & Hindia & 3 & 1.0 & 0 & 0 & 0 & 198.5 & 96.137 \\
8 & South of Karbala & 3 & 1.0 & 0 & 0 & 0 & 164 & 79.428 \\
9 & East of Karbala & 3 & 1.0 & 0 & 0 & 0 & 123 & 73.03 \\
10 & North of Karbala & 3 & 1.0 & 0 & 0 & 0 & 150.8 & 7.89 \\
11 & Al- Okhaider & 3 & 1.0 & 0 & 0 & 0 & 16.3 & 7 \\
\hline
\end{tabular}

Table (A.2). Karbala 132KV line data

\begin{tabular}{ccccc}
\hline Line no. & From Bus & To Bus & $\mathrm{R}(\mathrm{pu})$ & $\mathrm{X}(\mathrm{pu})$ \\
\hline 1 & 1 & 9 & 0.016367 & 0.091959 \\
2 & 1 & 10 & 0.021934 & 0.123238 \\
3 & 2 & 7 & 0.005479 & 0.030788 \\
4 & 3 & 4 & 0.009600 & 0.053939 \\
5 & 3 & 6 & 0.012024 & 0.067561 \\
6 & 3 & 10 & 0.015810 & 0.088831 \\
7 & 4 & 6 & 0.020985 & 0.117908 \\
8 & 5 & 9 & 0.007126 & 0.040038 \\
9 & 7 & 8 & 0.007744 & 0.043514 \\
10 & 8 & 6 & 0.005941 & 0.033380 \\
11 & 9 & 10 & 0.005567 & 0.031278 \\
12 & 10 & 11 & 0.039592 & 0.222454 \\
\hline
\end{tabular}

\section{ACKNOWLEDGEMENT}

The authors would like to thank the Electrical Transmission office for Karbala city and the Department of Electrical and Electronic Engineering, University of Karbala for their supports. 


\section{REFERENCES}

[1] Y. Al-Mahroqi, I. A. Metwally, A. Al-Hinai, and A. Al-Badi, "Reduction of Power Losses in Distribution Systems, World Academy of Science, Engineering and Technology," International Journal of Computer and Systems Engineering, vol. 6, no. 3, pp. 498-505, 2012.

[2] Y.M. Atwa, E.F. El-Saadany, M.M.A. Salama, R. Seethapathy, "Optimal renewable resources mix for distribution system energy loss minimization," IEEE Transactions on Power Systems, vol. 25, no. 1, pp. 360-370, 2010.

[3] T. Ackermann, G. Andersson, and L. Söder, "Distributed generation: A definition," Electric Power Systems Research, vol. 57, no. 3, pp. 195-204, 2001.

[4] I.S. Shahbudin et al., " FACTS device installation in transmission system using whale optimization algorithm," Bulleting of Electrical Engineering and Informatics, vol. 8, no. 1, pp. 30-38, 2019.

[5] Doagou-Mojarrad H, et al., "Optimal placement and sizing of DG (distributed generation) units in distribution networks by novel hybrid evolutionary algorithm," Journal Energy, vol. 54, pp. 129-138, 2013.

[6] L. Y. Wong, S. R. A. Rahim, Mohd. H. Sulaiman, and O. Aliman, "Distributed Generation Installation Using Particle Swarm Optimization," 4th International Power Engineering and Optimization Conf. (PEOCO2010), 2010.

[7] G. Pepermans, J. Driesen, D. Haeseldonckx, R. Belmans, and W. D'Haeseleer, "Distributed generation: Definition, benefits and issues," Energy Policy, vol. 33, no. 6, pp. 787-798, 2005.

[8] U. S. Department of Energy, "The Potential Benefits of Distributed Generation and the Rate-Related Issues That May Impede Its Expansion: A Report to the U.S. Congress Pursuant to Section 1817 of the Energy Policy Act of 2005," 2005.

[9] Fahad S. Abu-Mouti, and M. E. El-Hawary, "Optimal Distributed Generation Allocation and Sizing in Distribution Systems via Artificial Bee Colony Algorithm," IEEE Transactions on Power Delivery, vol. 26, no. 4, pp. 2090-2101, 2011.

[10] M. M. Aman, G. B. Jasmon, A. H. A. Bakar, and H. Mokhlis, "A new approach for optimum DG placement and sizing based on voltage stability maximization and minimization of power losses," Energy Conversion and Management, vol. 70, pp. 202-210, 2013.

[11] B. Banhthasit, C. Jamroen, and S. Dechanupaprittha, "Optimal Generation Scheduling of Power System for Maximum Renewable Energy Harvesting and Power Losses Minimization," International Journal of Electrical and Computer Engineering (IJECE), vol. 8, no. 4, pp. 1954-1966, 2018,

[12] V. V. Thong, J. Driesen, R. Belmans, "Transmission system operation concerns with high penetration level of distributed generation," 42nd International Universities Power Engineering Conference, pp. 867-871, 2007.

[13] A. M. El-Zonkoly, "Optimal placement of multi-distributed generation units including different load models using particle swarm optimization," Swarm and Evolutionary Computation, vol. 1, no. 1, pp. 50-59, 2011.

[14] Tuba Gözel, M. Hakan Hocaoglu, "An analytical method for the sizing and siting of distributed generators in radial systems," Electric Power Systems Research, vol. 79, no. 9, pp. 912-918, 2009.

[15] Naresh Acharya, Pukar Mahat, N. Mithulananthan, "An analytical approach for DG allocation in primary distribution network," Electrical Power and Energy Systems, vol. 28, no. 10, pp. 669-678, 2006.

[16] Z. Kamis, M. R. A. Ghani, M. N. Kamarudin, H. N. M. Shah, J. Zanariah, "A Review on SVC control for power system stability with and without auxiliary controller," Bulletin of Electrical Engineering and Informatics, vol. 8, no. 1, pp. 761-768, 2009.

[17] N. A. M. Kamari, I. Musirin, M. K. M. Zamani, and S. A. Halim, " Oscillation stability enhancement using multiobjective swarm based technique for smib system," Indonesian Journal of Electrical Engineering and Computer Science, vol. 16, no. 2, pp. 631-639, 2019.

[18] T. M. Shin, A. Adam, and A. F. Z. Abidin, "A comparative study of PSO, GSA and SCA in parameters optimization of surface grinding process," Bulletin of Electrical Engineering and Informatics, vol. 8, no. 3, pp. 1117-1127, 2019

[19] Z. T. Hasan, "Stability Enhancement Using Distributed Generation in Al Najaf Al-Ashraf Electrical Network," M.sc Thesis, University of Technology, 2014.

[20] R. Habachi, A. Touil, A. Boulal, A. Charkaoui, and A. Echchatbi, "Solving economic dispatch and unit commitment problem in smart grid system using eagle strategy based crow search algorithm," Indonesian Journal of Electrical Engineering and Computer Science, vol. 14, no. 3, pp. 1087-1096, 2019.

[21] M. Aliakbari, P. Maghouli, and H. A. Aalami, "Reliability Constrained Unit Commitment Considering the Effect of DG and DR Program," International Journal of Electrical and Computer Engineering (IJECE), vol. 8, no. 4, pp. 1985-1996, 2018.

[22] C. Shang, D. Srinivasan, and T. Reindl, "An improved particle swarm optimisation algorithm applied to battery sizing for stand-alone hybrid power systems," Electrical Power and Energy Systems, vol. 74, pp. 104-117, 2016.

[23] B. Singh, and D. K. Mishra, "A survey on enhancement of power system performances by optimally placed DG in distribution networks," Energy Reports, vol. 4, pp. 129-158, 2018.

[24] N. Khalesi, N. Rezaei, and M.-R. Haghifam, "DG allocation with application of dynamic programming for loss reduction and reliability improvement," Electrical Power and Energy Systems, vol. 33, pp. 288-295, 2011.

[25] P. Chiradeja, "Benefit of Distributed Generation: A Line Loss Reduction Analysis," IEEE/PES Transmission and Distribution Conference \& Exhibition: Asia and Pacific Dalian, 2005. 